\title{
Unemployment Anxiety of Student Taking Sports Education in University
}

\author{
Shalal Abdulla Mohammed ${ }^{1}$, Sebahattin Devecioglu ${ }^{2}$ \\ ${ }^{1}$ Institute of Health Sciences, Physical Eduation and Sports MA Program, Firat University, Turkey \\ ${ }^{2}$ Firat University, Faculty of Sports Sciences, Department of Sports Management, Elazig, Turkey \\ Correspondence: Sebahattin Devecioglu, Firat University, Faculty of Sports Sciences, Department of Sports \\ Management, Elazig, Turkey.
}

Received: April 2, 2018

Accepted: May 3, 2018

Online Published: May 7, 2018

doi:10.11114/jets.v6i7.3144

URL: https://doi.org/10.11114/jets.v6i7.3144

\begin{abstract}
Anxiety is one of the critical medical conditions that affect individuals due to various reasons. Some of these reasons may be related to inheritance while others are acquired during major life events. In this investigation, the level of unemployment anxiety was evaluated for students at Firat University, Elazı $\breve{g}$, Turkey. The study population comprised of 1161 students. The sampling of investigation consisted of 30\% of the population (333) students randomly selected from both genders. Spielberger State -Trait Anxiety Inventory (STAI) has been utilized for evaluating both state and unemployment anxiety levels. Furthermore, for analysing the results, SPSS 22.0 was applied. The null hypothesis in this research was considered as $(\mathrm{p}<.05)$ where any lower significance was considered as evidence proofing the existence of a relationship. The results revealed that there were significant relationships between the state anxiety and gender (for both male and female), age ranges (16-18) and (19-21), first and second educational years, job priorities (having a status and being a human useful for society), work experience, and for the hope of finding a job. On the other hand, significant relationships were found between the trait anxiety and both male and female students, age ranges (19-21), (22-25) and (26-28), study level, job priorities (earning money and being a human useful for society), work experience and the hope of finding a job.
\end{abstract}

Keywords: anxiety, sports sciences students, unemployment

\section{Introduction}

Employment is one of the biggest humanity concerns across the globe. The uncertainty related to the undertaken future created by the unemployment status has been an interesting area of research due to the caused impacts on human psychology and health (Eales, 1988). This fact is not only reflected by only the uncertainty of securing an adequate supply for basic life needs, but also for ensuring a level of decency, self-esteem, and self-realization which is a prestigious need everybody's life (Linn, Sandifer, \& Stein,1985). Indeed, the concept may have been changed over time; yet the unemployment is considered as a source of the chronic diseases and lack well-being (Gerdtham, \& Johannesson, 2003; Montgomery, Cook, Bartley, \& Wadsworth, 1999). Various studies investigated the effect of unemployment on individuals' health, which will be thoroughly discussed in chapter II. These studies, conducted in different countries, have recorded a number of possible diseases and psychological impacts due to the unemployment status. Accordingly, the range of impact may be in the form of stress, depression or anxiety, and in worse cases, it may cause hypertension, mental disorder and premature mortality (Linn, Sandifer, \& Stein, 1985; Gerdtham, \& Johannesson, 2003; Pharr, Moonie, \& Bungum, 2011). In most of these studies, it is noted that there is a correlation between the certain symptoms, some of which are mentioned above, and the unemployment status. However, the majority of these studies were targeting general unemployed individuals in a randomized fashion.

The investigation of physical and psychological of unemployment impacts may not only affect unemployed individuals, but it may also cause a sort of impact on university students who are still in their study phase (Choi, \& Lee, 2013). Here, the student may have various concerns related to future employment uncertainty and the fair of ending up unemployed. In fact, unemployment is recorded to be one of the factors causing students stress in different studies (Acharya, 2003; $\mathrm{Wu}, 2011)$. This in turns encourages the investigation and research in the area unemployment effects on college students. A number of factors can be considered as a suitable candidate in this case, for instance, stress level, depression, anxiety and/or trait anxiety. The insight in such research may open the door for further steps created by governmental and private institutions in an effort to help in solving this matter in future. 


\subsection{Anxiety and Anxiety Research}

Anxiety is a widely studied phenomenon in conjunction with various researches. It is proven that the anxiety, in many cases, affects different critical human choices and decisions (Williams, 2008; Schwarzer, 2000). According to the American Psychological Association, the anxiety is simply defined as "an emotion characterized by feelings of tension, worried thoughts and physical changes like increased blood pressure" (American Psychological Association[APA], 2017) while is defined by Merriam-Webster dictionary as "a strong desire sometimes mixed with doubt, fear, or uneasiness" (Merriam-Webster, 2017). Precisely, the state of worry, doubt, tension, fear, etc. all together as anxiety has been the source of several studies to anticipate its effect on human physical health, mental health, decision-making process and various types of reactions to other factors. It is generally known that the long term effects of anxiety may cause mental disorder and sever health diseases (Gerdtham, \& Johannesson, 2003). However, the level of anxiety varies based on the circumstances, living conditions, social and economic status (National Research Council [NRC], 2010). Anxiety level research has been widely investigated by different researchers and organizations, where it was discussed from different causing aspects, such as war (Abdel-Khalek, 2004; Zeidner, \& Ben-Zur, 1994), socio-economic (Norberg, Norton, Olivier, \& Zvolensky,2010; Frederick, \& Morrison,1996), education and certain courses in education (Hieronymus, 1951;- Spence, Taylor, \& Ketchel, 1956), marital status (Thoits, 1987; Scott et al., 2010), health status (Gorsuch, \& Key, 1974), and last but not least employment status (Linn, Sandifer, \& Stein, 1985; Pharr, Moonie, \& Bungum, 2011). Throughout these researches and many others, a number of measures were used to evaluate the level of anxiety. Perhaps the most commonly used measure is State-Trait Anxiety Inventory (STAI) which is discussed in the following subsection.

\subsection{The Stat-Trait Anxiety Inventory}

According to the American Psychological Association, STAI is famous frequently used measure for constructing anxiety research (Mykletun, 2009). This measure was developed by Spielberger et al., (1989). where the target was employing the measure clinical situation to properly diagnose the anxiety and differentiate it from other sources of distress ((Mykletun, 2009; APA, 1989; Spielberger, 1983). The developed idea by Spielberger et al., (1989). was originally based on a distinction concept proposed by Cattell and Scheier for state-trait research (Spielberger, 1989). The measure is essentially based on a questionnaire addressing feelings such as stress and worry which are directly related to anxiety. The measurement here considers the norm in the feelings i.e., the most positive and negative ends. Spielberger et al. developed a number of versions addressing state-trait anxiety; however, the most popular version Form Y ((Mykletun, 2009). Form Y consists of 40 points in total divided equally for assessing trait and state of anxiety. The questionnaire includes certain state anxiety measuring criteria such as "I feel calm; I feel secure" and "I am stressed; I am worried", and certain trait anxiety measuring criteria such as "I am a cool person; I am steady person" and "I worry too much over something that doesn't really matter". In this form, there is a four-point scale where it starts by "Almost Never" to "Almost Always" ((Mykletun, 2009).

\subsection{Problem Statement and Research Significance}

The college students' anxiety is cuased by different factors ranging from exams, social and economic status, income, accommodation, political stability, etc. However, the most influential factor, especial at senior education level, is the unemployment anxiety which is generated by the fair of not having a proper job after graduation. Having mentioned that, the idea of estimating the trait of anxiety in college students toward unemployment status needs to be investigated and discussed. This is essentially created by two main reasons, that is, the fact that there is no proper formal measurement applied for estimating the trait anxiety without conducting a proper survey, and the lack of formal results conducted by similar studies that may cope with the same issue. Therefore, conducting a survey study to identify the state and trait anxiety levels of college students is highly justified. This research becomes more interesting and beneficial when applied to sport education students as sport education departments could be the most joyful, energetic, and prone to lead their students to have less stress effect than other departments' students.

\subsection{Research Objectives}

This research is aiming at identifying the state and trait of anxiety levels of students of the Faculty of Sport Sciences Departments at Firat University - Turkey. As well as identifying the relationship between some factors like "hope of finding a job", "job priority" and "work experience.

\section{Research Methodology}

This research was based on a survey study that was conducted at the Faculty of Sport Sciences - Firat University, Elazı $\breve{g}$ Turkey. The survey was developed in order to determine the level of relationship, if available, between some factors such as "hope of finding a job", "job priority", "work experience", and "state and trait anxiety levels" of the students of Faculty of Sport Sciences. 


\subsection{Study Sample}

The study targeted students of Faculty of Sport Science - Firat University, Elazığ, Turkey; where there are four departments: Physical Education and Sport Teaching, Sports Management, Coaching Education, and Recreation with a total number of 1160 students. A random sampling method was applied in the initial phase where the students were given the option to participate or not, and those who did not participate were excluded from the evaluation.

\subsection{Questionnaire Form}

The questionnaire comprised the followings:

- Personal information: faculty, department, gender, age, and family income.

- Anxiety related information: anxiety about finding a job, work experiences, and job priorities.

\subsection{Evaluation Measures}

The following measures were utilized in the evaluation:

- STAI: Spielberger State-Trait Anxiety Inventory which was developed by Spielberger et al. in 1964 to determine the state and trait anxiety levels of the students.

- Turkish Reliability and Validity Scale Studies: Turkish reliability and validity scale studies were applied by Öner and Le Compte (1985) and Silverman, Saavedra and Pina (2001) to determine the test-retest stability coefficients are used in this research to conduct the analysis of the survey responses.

\subsection{Evaluation Tool}

The statistical package for the social science (SPSS) 22.0 software installed on ASUS-PC with i-7 Intel core @ 2.6GHz microprocessor speed. Several tests such as Frequency distributions, T-test, F-test, and Kolmogorov-Smirnov Test were conducted.

\section{Results and Analysis}

In this section, the obtained data was analyzed utilizing the STAI Inventory which developed in (Spielberger, 1989) and adapted to Turkish society studies in (Öner, \& Le Compte, 1985).

\subsection{Participants Details Analysis}

Table 1. Participants distribution details

\begin{tabular}{|c|c|c|c|}
\hline & Group & Frequency (f) & Percentage $(\%)$ \\
\hline \multirow{2}{*}{ Gender } & Male & 233 & 67.0 \\
\hline & Female & 110 & 33.0 \\
\hline \multirow[t]{5}{*}{ Age (year) } & $16-18$ & 24 & 7.2 \\
\hline & $19-21$ & 227 & 68.2 \\
\hline & $22-25$ & 56 & 16.8 \\
\hline & $26-28$ & 16 & 4.8 \\
\hline & $29+$ & 10 & 3.0 \\
\hline \multirow[t]{4}{*}{ Study level } & 1 & 57 & 17.1 \\
\hline & 2 & 207 & 62.0 \\
\hline & 3 & 68 & 20.4 \\
\hline & 4 & 1 & .30 \\
\hline \multirow[t]{5}{*}{ Job priority } & Earning money & 105 & 31.5 \\
\hline & Having a status & 79 & 23.7 \\
\hline & A tool for self-realization & 41 & 12.3 \\
\hline & Having social security & 20 & 6.0 \\
\hline & Being a human useful for society & 88 & 26.4 \\
\hline \multirow[t]{2}{*}{ Work experience } & Available & 187 & 56.2 \\
\hline & Not available & 146 & 43.8 \\
\hline \multirow[t]{2}{*}{ Hope of finding a job } & Yes & 232 & 69.7 \\
\hline & No & 101 & 30.3 \\
\hline Total & & 333 & 100.0 \\
\hline
\end{tabular}

The distribution of the participants are displayed in table 1 . It can be seen that $67.0 \%$ of the participants are male (233 respondents out of the total 333 participants) while $33.0 \%$ are females (110 participants out of the total 333 participants). In addition, the highest majority of age category were 19-21 years which is represented by 227 students $(68.2 \%)$ followed by 22-25 years range which is composed of 56 students comprised $16.8 \%$. While 24 students $(7.2 \%)$ of the participants are aged 16-18 years old, 16 students $(4.8 \%)$ are in the 26-28 range. Finally, $3.0 \%$ of the total participants (10 students) are 29 and older. 
It is also exhibited that the distributions of the participants over study levels were composed of $57(17.1 \%)$ participants from the first year students, 207 (62.0\%) participants from the second year students, 68 participants $(20.4 \%)$ from the third year and only $1(0.3 \%)$ student from the fourth year students.

Regarding the job priority statement, the response were 105 (30.5\%) for money earning reason, $79(23.7 \%)$ for having a status reason, $41(12.3 \%)$ for a tool for self-realization reason, $20(6.0 \%)$ for social security reason, and finally 88 $(26.4 \%)$ chose to be a useful human for the society.

In addition, it demonstrates that while $187(56.2 \%)$ students had work experience, 146 (43.8\%) participants were recorded no job experience. This indicates that more than the half of the participants have a previous and/current job experience.

A considerable majority of the participants are hopeful for finding a job. This is reflected by $232(69.7 \%)$ participants while $101(30.3 \%)$ participants are not hoping for an upcoming job during their study or after graduation.

\subsection{State Anxiety Frequency Analysis}

Regarding the frequencies distribution of statements of the S-Anxiety, the detailed results are presented in table 2.

Table 2. S-Anxiety questionnaire statements frequencies, median and standard deviation

\begin{tabular}{|c|c|c|c|c|c|c|c|c|c|c|c|}
\hline \multirow{2}{*}{$\begin{array}{l}\text { S-Anxiety Questionnaire } \\
\text { Statements }\end{array}$} & \multicolumn{2}{|c|}{ Not at all } & \multicolumn{2}{|c|}{ Somewhat } & \multirow{2}{*}{$\begin{array}{l}\text { Very } \\
\text { so } \\
\text { F }\end{array}$} & \multirow{2}{*}{$\begin{array}{l}\text { Much } \\
\%\end{array}$} & \multicolumn{2}{|c|}{ Completely } & \multicolumn{2}{|c|}{$\begin{array}{l}\text { median and } \\
\text { deviation }\end{array}$} & \multirow{2}{*}{$\begin{array}{l}\text { standard } \\
\sigma^{-2}\end{array}$} \\
\hline & $\mathrm{F}$ & $\%$ & $\mathrm{~F}$ & $\%$ & & & $\mathrm{~F}$ & $\%$ & $\mathrm{~N}$ & Mean & \\
\hline 1. I am calm right now & 93 & 27.9 & 101 & 30.3 & 65 & 19.5 & 74 & 22.2 & 333 & 2.36 & 1.112 \\
\hline 2. I feel safe & 62 & 18.6 & 97 & 29.1 & 82 & 24.6 & 92 & 27.6 & 333 & 2.61 & 1.080 \\
\hline 3. I feel nervous right now & 105 & 31.5 & 90 & 27.0 & 88 & 26.4 & 50 & 15.0 & 333 & 2.25 & 1.059 \\
\hline 4. I feel regret & 110 & 33.0 & 88 & 26.4 & 80 & 24.0 & 55 & 16.5 & 333 & 2.24 & 1.085 \\
\hline 5. I am in peace right now & 94 & 28.2 & 123 & 36.9 & 69 & 20.7 & 47 & 14.1 & 333 & 2.21 & 1.007 \\
\hline 6. I don't feel good right now & 92 & 27.6 & 103 & 30.9 & 81 & 24.3 & 57 & 17.1 & 333 & 2.31 & 1.054 \\
\hline $\begin{array}{l}\text { 7. I am worried about what will } \\
\text { happen to me }\end{array}$ & 112 & 33.6 & 95 & 28.5 & 70 & 21.0 & 56 & 16.8 & 333 & 2.21 & 1.086 \\
\hline 8. I feel rested & 126 & 37.8 & 108 & 32.4 & 61 & 18.3 & 38 & 11.4 & 333 & 2.03 & 1.010 \\
\hline 9. I am anxious right now & 81 & 24.3 & 104 & 31.2 & 94 & 28.2 & 54 & 16.2 & 333 & 2.36 & 1.022 \\
\hline 10. I feel comfortable & 89 & 26.7 & 125 & 37.5 & 65 & 19.5 & 54 & 16.2 & 333 & 2.36 & 1.025 \\
\hline 11. I have self-confidence & 74 & 22.2 & 94 & 28.2 & 87 & 26.1 & 78 & 23.4 & 333 & 2.25 & 1.080 \\
\hline 12. I get nervous right now & 92 & 27.6 & 103 & 30.9 & 92 & 27.6 & 46 & 13.8 & 333 & 2.28 & 1.016 \\
\hline 13. I am so angry & 95 & 28.5 & 123 & 36.9 & 73 & 21.9 & 42 & 12.6 & 333 & 2.19 & .989 \\
\hline 14. I feel I am very nervous & 87 & 26.1 & 110 & 33.0 & 95 & 28.5 & 41 & 12.3 & 333 & 2.22 & .984 \\
\hline 15. I feel comforted & 85 & 25.5 & 126 & 37.8 & 86 & 25.8 & 36 & 10.8 & 333 & 2.26 & .949 \\
\hline $\begin{array}{l}\text { 16. I feel content with my } \\
\text { situation right now }\end{array}$ & 90 & 27.0 & 115 & 34.5 & 81 & 24.3 & 47 & 14.1 & 333 & 2.28 & 1.008 \\
\hline 17. I am worried right now & 80 & 24.0 & 122 & 36.6 & 88 & 26.4 & 43 & 12.9 & 333 & 2.28 & .972 \\
\hline $\begin{array}{l}\text { 18. I feel nonplussed because of } \\
\text { excitement }\end{array}$ & 109 & 32.7 & 101 & 30.3 & 88 & 26.4 & 35 & 10.5 & 333 & 2.15 & .997 \\
\hline 19. I am joyful right now & 102 & 30.6 & 127 & 38.1 & 67 & 20.1 & 37 & 11 . & 333 & 2.12 & .970 \\
\hline 20. I am in a good mood right & 101 & 30.3 & 91 & 27.3 & 88 & 26.4 & 53 & 15.9 & 333 & 2.28 & 1.063 \\
\hline
\end{tabular}
now

As it is demonstrated in table 2, there is an approximately moderate uniform mean distribution for all S-Anxiety statements responses provided by all participants. The highest selected response belongs to "I am joyful right now" with the choice of "Somewhat" where the frequency found here is $127(38.1 \%)$. The lowest frequency goes to "I feel comforted" with the option "completely" where only $36(10.1 \%)$ highlighted this option. This is actually true, as the life of students is usually uncomfortable and passes with a lot of troubles and stress.

\subsection{Trait-Anxiety Frequency Analysis}

Similarly, the T-Anxiety frequency distribution for the questionnaire statements responses is provided in Table 3.

As shown in Table 3, the highest frequently ticked response is "I usually get tired quickly" with the option "sometimes" where the frequency here is $149(44 \%)$. This is due to the fact that the stressful life of students implies that they feel tired from time to time, even without giving any excessive effort. Interestingly, it can also be noted that the lowest frequency in Table 6 goes to "I usually feel tired quickly" but with the option "almost always" where the frequency here is $24(7.2 \%)$. This is also implied by the fact that although students do have a stressful education environment and conditions, they tend to quickly give up frustrate. 
Table 3. T-Anxiety questionnaire statements frequencies, median and standard deviation

\begin{tabular}{|c|c|c|c|c|c|c|c|c|c|c|c|}
\hline \multirow{2}{*}{$\begin{array}{l}\text { T-Anxiety Questionnaire } \\
\text { Statements }\end{array}$} & \multicolumn{2}{|c|}{$\begin{array}{l}\text { Almost } \\
\text { never }\end{array}$} & \multicolumn{2}{|c|}{ Sometimes } & \multicolumn{2}{|c|}{ Often } & \multicolumn{2}{|c|}{$\begin{array}{l}\text { Almost } \\
\text { always }\end{array}$} & \multicolumn{2}{|c|}{$\begin{array}{l}\text { median and } \\
\text { deviation }\end{array}$} & \multirow{2}{*}{$\begin{array}{c}\text { standard } \\
\sigma^{2}\end{array}$} \\
\hline & $\mathrm{f}$ & $\%$ & $\mathrm{~F}$ & $\%$ & $\mathrm{~F}$ & $\%$ & $\mathrm{f}$ & $\%$ & $\mathrm{~N}$ & Mean & \\
\hline 21. I usually feel good & 43 & 12.9 & 126 & 37.8 & 119 & 35.7 & 45 & 13.5 & 333 & 2.50 & .781 \\
\hline 22. I usually get tired quickly & 66 & 19.8 & 149 & 44.4 & 94 & 28.2 & 24 & 7.2 & 333 & 2.23 & .719 \\
\hline 23. I usually cry easily & 84 & 25.2 & 114 & 34.2 & 83 & 24.9 & 52 & 15.6 & 333 & 2.31 & 1.034 \\
\hline 24. I would like to be happy as others & 57 & 17.1 & 109 & 23.7 & 101 & 30.3 & 66 & 19.8 & 333 & 2.53 & .991 \\
\hline $\begin{array}{l}\text { 25. I miss the opportunities because I can't } \\
\text { decide quickly }\end{array}$ & 62 & 18.6 & 124 & 37.2 & 92 & 27.6 & 55 & 16.5 & 333 & 2.42 & .949 \\
\hline 26. I feel rested & 62 & 18.8 & 135 & 40.5 & 82 & 24.6 & 54 & 16.2 & 333 & 2.38 & .939 \\
\hline $\begin{array}{l}\text { 27. I am usually calm, self-possessed and } \\
\text { cold-minded }\end{array}$ & 45 & 13.5 & 116 & 34.8 & 97 & 29.1 & 75 & 22.5 & 333 & 2.61 & .962 \\
\hline $\begin{array}{l}\text { 28. I feel that the difficulties have } \\
\text { accumulated as much as I cannot get over }\end{array}$ & 54 & 16.2 & 122 & 36.6 & 99 & 29.7 & 58 & 17.4 & 333 & 2.48 & .925 \\
\hline 29. I worry about trivial things & 72 & 21.6 & 118 & 35.4 & 85 & 25.5 & 58 & 17.4 & 333 & 2.39 & 1.021 \\
\hline 30. I am usually happy & 53 & 15.9 & 113 & 33.9 & 108 & 32.4 & 59 & 17.7 & 333 & 2.52 & .925 \\
\hline $\begin{array}{l}\text { 31. I take everything seriously and become } \\
\text { anxious }\end{array}$ & 53 & 15.9 & 118 & 35.4 & 97 & 29.1 & 65 & 19.5 & 333 & 2.52 & .961 \\
\hline 32. I usually have no self-confidence & 94 & 28.2 & 94 & 28.2 & 86 & 25.8 & 59 & 17.7 & 333 & 2.33 & 1.144 \\
\hline 33. I usually feel safe & 43 & 12.9 & 117 & 35.1 & 108 & 32.4 & 65 & 19.5 & 333 & 2.59 & .894 \\
\hline $\begin{array}{l}\text { 34. I avoid encountering distressed and } \\
\text { difficult situations }\end{array}$ & 70 & 21.0 & 108 & 32.4 & 94 & 28.2 & 61 & 18.3 & 333 & 2.44 & 1.036 \\
\hline 35. I usually feel sad & 58 & 17.4 & 132 & 39.6 & 84 & 25.2 & 59 & 17.7 & 333 & 2.43 & .951 \\
\hline 36. I am usually pleased with my life & 38 & 11.4 & 114 & 34.2 & 117 & 35.1 & 64 & 19.2 & 333 & 2.62 & .850 \\
\hline 37. Unnecessary thoughts disturb me & 47 & 14.1 & 135 & 40.5 & 94 & 28.2 & 57 & 17.1 & 333 & 2.48 & .877 \\
\hline $\begin{array}{l}\text { 38. I take my frustrations so seriously that I } \\
\text { never forget }\end{array}$ & 56 & 16.8 & 111 & 33.3 & 101 & 30.3 & 65 & 19.5 & 333 & 2.53 & .979 \\
\hline $\begin{array}{l}\text { 39. I am a rightminded and determined } \\
\text { person }\end{array}$ & 38 & 11.4 & 103 & 30.9 & 117 & 35.1 & 75 & 22.5 & 333 & 2.69 & .879 \\
\hline $\begin{array}{l}\text { 40. I worry about the issues that occupy my } \\
\text { mind recently }\end{array}$ & 48 & 14.4 & 107 & 32.1 & 100 & 30.0 & 78 & 23.4 & 333 & 2.62 & .994 \\
\hline
\end{tabular}

\subsection{State Anxiety Correlation Analysis}

In order to understand the relationship between all considered factors and the S-Anxiety, correlation analyses have been conducted. These analyses elaborate the existence of any significant relationship. The application of Kolmogorov-Smirnov (K-S) test is providing the detailed needed information on the relationship between different cases.

3.4.1 Correlation Analysis for S - Anxiety and Gender

Table 4. Normality test (K-S) for the Gender vs S-Anxiety

\begin{tabular}{llllll}
\hline Normality test & & \multicolumn{2}{l}{ Kolmogorov-Smirnov } & & \\
\cline { 3 - 4 } State - Anxiety & Gender & Df & Sig. & Variance \\
& & & & & \\
& Male & 223 & .001 & -.4215 & 94.398 \\
& Female & 110 & .006 & -.0818 & 114.993 \\
\hline
\end{tabular}

Table 4 shows the test of normality that provides df as well as the significance considering the gender and the S-Anxiety. As it can be clearly seen from K-S analysis, the significance level for male students is provided by 0.001 which is less 
the needed threshold $(\mathrm{p}<0.05)$. However, this tends to fade away a little bit in female students as the significance is 0.006 .

3.4.2 Correlation Analysis for $\mathrm{S}$ - Anxiety and Age

Table 5. Normality test (K-S) for the Age vs S-Anxiety

\begin{tabular}{|c|c|c|c|c|c|}
\hline \multirow[t]{2}{*}{ Normality Test } & \multicolumn{4}{|c|}{ Kolmogorov-Smirnov } & \multirow[b]{2}{*}{ Variance } \\
\hline & Age & Df & Sig. & Mean & \\
\hline \multirow[t]{5}{*}{ State - Anxiety } & $16-18$ & 24 & .023 & -.1667 & 61.101 \\
\hline & $19-21$ & 227 & .005 & -.1564 & 110.701 \\
\hline & $22-25$ & 56 & .081 & -2.4464 & 95.561 \\
\hline & $26-28$ & 16 & .200 & 3.9375 & 57.396 \\
\hline & $29+$ & 10 & .200 & 4.500 & 20.278 \\
\hline
\end{tabular}

Table 5 displays the test of normality where the $\mathrm{df}$ as well as the significance considering the S-Anxiety with respect to the age. It is displayed that the age ranges of 16-18 and 19-21 satisfy the condition for fulfilling null hypothesis rejection. The smallest significance is obtained at age range 19-21 which is exactly 0.005 ; apart from age range effects on S-Anxiety, it is also clear that the highest percentage of frequency happens in the same range. This may be another reason for anxiety tendency which is highly satisfying the condition to claim that there is a significant relationship.

3.4.3 Correlation Analysis for S - Anxiety and Study Level

Table 6. Normality test (K-S) for the Study level vs S-Anxiety

\begin{tabular}{llllll}
\hline $\begin{array}{l}\text { Normality } \\
\text { Test }\end{array}$ & Level & \multicolumn{2}{l}{ Kolmogorov-Smirnov } & Mean & Variance \\
\hline State & 1 & Df & Sig. & -5.632 & 74.094 \\
Anxiety & 2 & 57 & .005 & -.966 & 102.381 \\
& 3 & 207 & .000 & 2.353 & 78.053 \\
& 4 & 68 & .200 & - & -
\end{tabular}

The relationship between the educational level (first, second, third and fourth years) are provided in table 7. As it can be seen from table 7, the details of S-Anxiety for the fourth year has been omitted as it is provided by only one respondent, and there can be no judgment as the anxiety here is constant. In addition, a significant level of 0.000 is obtained from level 2 (second year) which implies that the null hypothesis can be rejected here. Therefore, level 2 (second year) has a strong relationship with S-Anxiety towards the future employment. In addition, level 1 has a significance of 0.005 which is not adequate for refuting the null hypothesis

3.4.4 Correlation Analysis for $\mathrm{S}$ - Anxiety and Job Priorities

Table 7. Normality test (K-S) for the Job priority vs S-Anxiety

\begin{tabular}{llllll}
\hline Normality test & & \multicolumn{2}{l}{ Kolmogorov-Smirnov } & & \\
& Job priority & Df & Sig. & Mean & Variance \\
\hline State - Anxiety & Earning money & 105 & .062 & .267 & 84.024 \\
& Having a status & 79 & .031 & -.582 & 102.381 \\
& A tool for self-realization & 41 & .200 & 2.317 & 8.287 \\
& Having a social security & 20 & .024 & 1.700 & 133.274 \\
& Being a human useful for society & 88 & .162 & -2.4318 & 107.398 \\
\hline
\end{tabular}

Table 7 displays the relationship between the S-Anxiety and job priorities (earning money, having a status, a tool for self-realization, having a social security, and being a human useful for society). Basically, the results of the participants' responses analyses here are straightforward. Two the options succeeded in providing the required significance level to base an argument for having a direct relationship with the S-Anxiety. These two options are "Having a status" where the significance is .031 and "Having a social security" where the significance is 0.024 .

\subsubsection{Correlation Analysis for $\mathrm{S}$ - Anxiety and Work Experience}

Table 8. Normality test (K-S) for the Work experience vs S-Anxiety

\begin{tabular}{llllll}
\hline Normality Test & \multicolumn{4}{c}{ Kolmogorov-Smirnov } \\
& Work Experience & Df & Sig. & Mean & Variance \\
\hline State - Anxiety & Available & 187 & .034 & -1.321 & 95.391 \\
& Not available & 146 & .000 & .9863 & 105.655 \\
\hline
\end{tabular}

Table 8 shows the relationship between the S-Anxiety and work experience (available or not available). The relationship here is quite obvious, as there is a significance level of 0.000 which is way much below the adequate $(p<0.05)$ for "not available" option. Meaning that there is a direct relationship between the S-Anxiety level and the lack of previous work experience. Similarly, in the case of the availability of work experience, the significance level is adequate for refuting 
the null hypothesis. This indicates that the S-Anxiety level is negatively affected by the availability of work experience, however, less than in the case of lack of any work experience

\subsubsection{Correlation Analysis for S - Anxiety and Hope of Finding a Job}

Table 9. Normality test (K-S) for the Hope of finding a job vs S-Anxiety

\begin{tabular}{llllll}
\hline Normality test & \multicolumn{4}{l}{ Kolmogorov-Smirnov } & \\
& Hope of finding a job & Df & Sig. & Mean & Variance \\
\hline State - Anxiety & Yes & 232 & .000 & -2.151 & 103.878 \\
& No & 101 & .092 & 3.921 & 69.094 \\
\hline
\end{tabular}

Table 9 presents the relationship between the S-Anxiety and hope of finding a job (yes or no). The relationship here is quite obvious, as there is a significance level of .000 which is a way much below the adequate $(\mathrm{p}<.05)$ for the "yes" option. Meaning that there is a direct relationship between the S-Anxiety level and the hope of finding a job for the affirmative answer "yes". In contrast, in the case of there is no hope of finding a job or it has not been yet planned in the mind of the participant, the significance level is not adequate for refuting the null hypothesis. This indicates that the S-Anxiety level is not negatively affected by the lack of hope for finding a job in future yet it is directly affected by the existence of this hope

\subsection{Trait Anxiety Correlation Analysis}

In order to under to understand the relationship between all considered 7 factors and the T-Anxiety, correlation analyses have been conducted. These analyses elaborate the existence of any significant relationship. The application of Kolmogorov-Smirnov (K-S) test is providing the detailed needed information on the relationship between different cases.

\subsubsection{Correlation Analysis for T - Anxiety and Gender}

Table 10. Normality test (K-S) for the Gender vs T-Anxiety

\begin{tabular}{llllll}
\hline Normality Test & \multicolumn{5}{c}{ Kolmogorov-Smirnov } \\
& Gender & Df & Sig. & Mean & Variance \\
\hline Trait - Anxiety & Male & 223 & .000 & 13.354 & 45.329 \\
& Female & 110 & .026 & 14.7364 & 47.260
\end{tabular}

Table 10 shows the test of normality that provides $\mathrm{df}$ as well as the significance considering the gender and the T-Anxiety. As it can be clearly seen from the K-S test, the significance level for male students is provided by .000 which is less the needed threshold $(\mathrm{p}<0.05)$. In the same time, this tends to fade away a little bit in female students as the significance is .026; yet, it is still satisfying the case $(\mathrm{p}<0.05)$.

3.5.2 Correlation Analysis for T - Anxiety and Age

Table 11. Normality test (K-S) for the Age vs T-Anxiety

\begin{tabular}{llllll}
\hline Normality test & \multicolumn{4}{l}{ Kolmogorov-Smirnov } \\
& Age & df & Sig. & Mean & Variance \\
\hline Trait - Anxiety & $16-18$ & 24 & .129 & 13.750 & 55.674 \\
& $19-21$ & 227 & .003 & 13.414 & 52.447 \\
& $22-25$ & 56 & .039 & 14.035 & 19.381 \\
& $26-28$ & 16 & .006 & 15.875 & 39.050 \\
& $29+$ & 10 & .200 & 18.444 & 28.044 \\
\hline
\end{tabular}

Table 11 demonstrates the test of normality where the $\mathrm{df}$ as well as the significance considering the T-Anxiety with respect to the age. As it can be clearly seen from K-S analysis, the significance levels range based on the age. However, three ranges satisfy the condition for fulfilling the null hypothesis rejection, which is (19-21) where the significance falls to 0.003 , (22-25) where the significance falls to .039 , and (26-28) where the significance falls to 0.006 . Therefore, these age ranges prone to have $\mathrm{T}$ - Anxiety level. In fact, this is a natural conclusion as at these age ranges students become highly concerned about their future employments. In addition, it is interesting that the age range 29+ is showing a high significance level where it does not tend to have $\mathrm{T}$ - Anxiety. This is due to two main reasons, most of the participants in age range are already employed and the number of participants is quite small $(n=10)$ compared to other ranges.

\subsubsection{Correlation Analysis for T - Anxiety and Study Level}

The relationship between the educational level (first, second, third and fourth years) are displayed in table 12.

As it can be seen from table 12, the details of the T-Anxiety for the fourth year has been omitted as it is provided by only one respondent, and there can be no judgment as the anxiety here is constant. In addition, a significant level of .000 
is obtained from level 2 (second year) which implies that the null hypothesis can be strongly rejected here. Therefore, level 2 (second year) has a strong relationship with T-Anxiety towards the future employment. In addition, level 1 has a significance of .005 and level 3 has a significance of .006 which are adequate for refuting the null hypothesis as well. This implies that all educational levels, except the excluded $4^{\text {th }}$ level, are directly related to $\mathrm{T}$ - Anxiety.

Table 12. Normality test (K-S) for the Study level vs T-Anxiety

\begin{tabular}{llllll}
\hline Normality test & Level & \multicolumn{3}{l}{ Kolmogorov-Smirnov } & \\
& & df & Sig. & Mean & Variance \\
\hline State - Anxiety & 1 & 57 & .005 & 11.877 & 63.967 \\
& 2 & 207 & .002 & 13.980 & 43.990 \\
& 3 & 68 & .006 & 15.029 & 34.775 \\
& 4 & - & - & - & - \\
\hline
\end{tabular}

3.5.4 Correlation Analysis for T - Anxiety and Job Priorities

Table 13. Normality test (K-S) for The Job priority vs T-Anxiety

\begin{tabular}{llllll}
\hline Normality Test & Job priority & \multicolumn{2}{l}{ Kolmogorov-Smirnov } & & \\
& & df & Sig. & Mean & Variance \\
\hline State - Anxiety & Earning money & 105 & .021 & 14.057 & 54.227 \\
& Having a status & 79 & .059 & 12.772 & 41.000 \\
& A tool for self-realization & 41 & .200 & 14.658 & 34.080 \\
& Having a social security & 20 & .200 & 15.8116 & 27.145 \\
& Being a human useful for society & 88 & .001 & 13.727 & 51.005 \\
\hline
\end{tabular}

Table 13 demonstrates the relationship between the T-Anxiety and job priorities (earning money, having a status, a tool for self-realization, having a social security, and being a human useful for society) are provided in. Basically, the results of the participants' responses analyses here are straightforward. Only two of the options succeeded in providing the required significance level to base an argument for the T-Anxiety. These options are "Being a human useful for society" with a significance level of .001 and "Earning money" with a significance level of .021 . These two cases satisfy the condition for rejecting the null hypothesis. Thus, it can be said there a strong correlation between "Earning money" and "Being a human useful for society" and the level of T - Anxiety. This is due to the fact that students usually have a major concern on how they can earn money and how they benefit their society when they get their jobs.

\subsubsection{Correlation Analysis for T - Anxiety and Work Experience}

Table 14. Normality test (K-S) for the Work experience vs T-Anxiety

\begin{tabular}{|c|c|c|c|c|c|}
\hline \multirow[t]{2}{*}{ Normality Test } & \multirow[t]{2}{*}{ Work Experience } & \multicolumn{4}{|c|}{ Kolmogorov-Smirnov } \\
\hline & & Df & Sig. & Mean & Variance \\
\hline \multirow{2}{*}{ State - Anxiety } & Available & 187 & .000 & 13.395 & 48.434 \\
\hline & Not available & 146 & .014 & 14.342 & 43.261 \\
\hline
\end{tabular}

The relationship between the T-Anxiety and work experience (available or not available) are exhibited in table 14 . The relationship here is quite obvious, as there is a significance level of .000 which is way much below the adequate $(\mathrm{p}<.05)$ for "available" option. Meaning that there is a direct relationship between the T-Anxiety level and the availability of previous work experience. Moreover, in the case of the lack of previous work experience, the significance level is also adequate for refuting the null hypothesis where the significance is .014. This indicates that the T-Anxiety level is negatively affected both options of having work experience or not.

3.5.6 Correlation Analysis for $\mathrm{T}$ - Anxiety and Hope of Finding a Job

Table 15. Normality test (K-S) for the Hope of finding a job vs T-Anxiety

\begin{tabular}{llllll}
\hline Normality Test & The hope of finding a job & \multicolumn{2}{l}{ Kolmogorov-Smirnov } & & \\
& & df & Sig. & Mean & Variance \\
\hline State - Anxiety & Yes & 232 & .000 & 13.099 & 50.098 \\
& No & 101 & .017 & 15.445 & 33.950 \\
\hline
\end{tabular}

Table 15 presents the relationship between the T-Anxiety and hope of finding a job (yes or no). The relationship here is quite obvious, as there is a significance level of .000 which is a way much below the adequate $(p<.05)$ for the "yes" option. Meaning that there is a direct relationship between the T-Anxiety level and the hope of finding a job for the affirmative answer "yes". Moreover, in the case of there is no hope of finding a job or it has not been yet planned in the mind of the participant, the significance level is also adequate for refuting the null hypothesis. This indicates that the T-Anxiety level is negatively affected by both statuses of the hope for finding a job in future. 


\section{Discussion}

The administered research questionnaire of this study targeted a sample of $N=333$ students from the Faculty of Sport Sciences - Firat University. The responses were used to evaluate the correlation between seven considered factors: gender, age, department, study level, job priority, work experience, and the hope of finding a job, and both the state and trait anxiety levels. The used measure was the standard STAI forms for state and trait anxieties (Spielberger, 1989) and it was applied in Turkish version provided in (Öner, N., \& Le Compte, 1985).

The demographic analysis of the used sample shows that the sample was constituted of 233 male students (67.0\%) and 110 female students $(33.0 \%)$. The highest range of age was residing within 19-21 years' level with 227 students constituting $68.2 \%$ of the total number. At the same time, the age ranges 16-18 and 29+ composed $24(7.2 \%)$ and 10 (3.0\%) respectively. This was due to the fact that undergraduate studies in Turkey generally fall within the age range 19-21. The highest level of students was fallen in the second educational year where 207 students $(62.0 \%)$ of the total sample population was participated. Nevertheless, only one student from the fourth year had joined the administered survey constituting an insignificant level of $0.3 \%$ of the overall population.

More than half of the participants (56.2\%) had work experience while 146 students (43.8\%) had no work experience. The same participants responded to the job priority as the followings: the majority of the responses went to "earning money" where 105 students ( $31.5 \%)$ had considered this option. In the same time, only 20 students $(6.0 \%)$ considered "having a social security" as job priority in their response. Finally, more than two-third of the whole sample population was hopeful to find a job where $232(69.7 \%)$ responded with "yes" and 101 (30.3\%) responded by "no".

The frequencies distribution of state anxiety questionnaire items were relatively uniform in distribution. The highest frequency went to "Somewhat" for "I am joyful right now" where 127 students chose this option comprising $38.1 \%$ of the total percentage. On the other hand, the lowest frequency went to "Completely" for "I feel comforted" where 36 students chose this option comprising $10.1 \%$ of the total percentage. Other frequencies range between these two extreme responses with a mean in the range of 2.03 to 2.61 .

Similarly, the trait anxiety analysis indicated a coparatively uniform distribution as well. The highest frequency was highlighted for "Sometimes" as a response to "I usually get tired quickly". The recorded frequency for this option was 149 or $44 \%$ approaching from the half of all students. It is interesting to indicate that the lowest frequency was assigned to "almost alway" as a response to "I usually feel tired quickly". The frequency here was 24 which is $7.2 \%$ of the total sample population. The result obtained here according to the fact that Sport Sciences students are usually trained not to feel tired quickly as it is part of their future career and life. Apart from these extreme results, the means of all frequencies range from 2.23 and 2.69 .

The correlations of the seven considered factors were found using K-S test assuming a normal distribution and based on a null hypothesis to be rejected in cases $(\mathrm{p}<0.05)$. Accordingly:

- The gender was correlated with both state and trait anxieties where significant correlations were found for both males and female students enable the rejection of the null hypothesis, as shown in Table 1 and 4 . This indicates that both genders are prone to have state and trait anxieties towards unemployment status in future.

- The age was shown to be correlated with both state and trait anxieties, however not in a complete match for both cases. The age ranges of (16-18) and (19-21) were correlated to the state anxiety, as shown in Table 5. However, the age ranges (19-21), (22-25) and (26-28) were correlated with the trait anxiety, as presented in Table 11.

- The educational levels have also shown distinguished correlations with both state and trait anxieties. The direct relationship between the state anxiety and both first and second educational years, as shown in Table 6. Yet, the correlation between trait anxiety and first, second and third educational years was proved in Table 12.

- Not all job priority options succeeded in passing the null hypothesis rejection. Only "having a status" and "having a social security" were shown to be correlated to the state anxiety, as presented in Table 7. However, the correlated options with trait anxiety were "earning money" and "being a human useful for society", as presented in Table 13.

- Both options of work experience (available and not available) were proved to be correlated with both state and trait anxieties as presented in Tables 8 and 14 .

- The positive feelings towards the hope of finding a job were related to the state anxiety level, while the negative feelings towards the hope of finding a job were proved to be insignificantly related to state anxiety level, as shown in Table 9. Nevertheless, both positive and negative feelings towards the hope of finding a job were correlated to the trait anxiety, as shown in Table 15. 


\section{Conclusions}

One of the serious medical conditions that impacts individuals because of various reasons is Anxiety. While some of these are acquired throughout major life events, others causes might be associated with inheritance. The level of unemployment anxiety was evaluated for students at the Firat University, Van, Turkey. Three hundred and thirty three students participated from the department of physical education. Spielberger State -Trait Anxiety Inventory (STAI) has been utilized for evaluating both state and unemployment anxiety levels. the results revealed that, the relationships between the state anxiety and gender (for both male and female), age ranges (16-18) and (19-21), Departments (Sports Management I, Coaching Education I and II, and Recreation I), first and second educational years, job priorities (having a status and being a human useful for society), work experience, and for the hope of finding a job were significant. On the other hand, the findings also unveiled that relationships were obtained between the trait anxiety and both male and female students, age ranges (19-21), (22-25) and (26-28), Departments (Physical Education and Sport Teaching I and Recreation I), study level, job priorities (earning money and being a human useful for society), work experience and the hope of finding a job.

Lastly, the results of this research can be widely utilized in academia and academic research, as various factors along with their sub-factors have been studied in relationship with both state and trait anxieties. One of the aspects that have not been properly tackled within this study is the deep investigation of job priority options as they may be a great motive for both state and trait anxieties. This can be a direction for a future research in this field. In addition, there were no adequate participants from the fourth year. Therefore, the exact reflection of the fourth year as an educational level was not properly addressed.

\section{Acknowledgements}

This article was produced from Institute of Health Sciences, Physical Eduation and Sports MA Program, Firat University, Turkey, Master Thesis: Unemployment Anxieties Of Students Taking Sports Education In Firat University

\section{References}

Abdel-Khalek, A. M. (2004). Does war affect death anxiety level? Seven readings of measurements (1988-2002) before and after the Iraqi invasion of Kuwait. OMEGA-Journal of Death and Dying,49(4), 287-297. https://doi.org/10.2190/RL7Q-GYXQ-DDQJ-LV8N

Acharya, S. (2003). Factors affecting stress among Indian dental students. Journal of dental education, 67(10), 1140-1148.

American Psychological Association. Anxiety. [Online]. Available at http://www.apa.org/topics/anxiety/ (Accessed on $17^{\text {th }}$ Jan. 2017).

American Psychological Association. The State-Trait Anxiety Inventory (STAI), Construct: Adult anxiety. [Online]. Available at http://www.apa.org/pi/about/publications/caregivers/practice-settings/assessment/tools/trait-state.aspx (Accessed on $17^{\text {th }}$ Jan. 2017)

Choi, S. H., \& Lee, H. (2013). Affecting factors in unemployment stress among college students- focused on physical symptoms, depression, anxiety and self-esteem.The Journal of the Korea Contents Association, 13(12), 808-816. https://doi.org/10.5392/JKCA.2013.13.12.808

Eales, M. (1988). Depression and anxiety in unemployed men. Psychological Medicine, 18(4), 935-945. https://doi.org/10.1017/S0033291700009867

Frederick, C. M., \& Morrison, C. S. (1996). Social physique anxiety: Personality constructs, motivations, exercise attitudes, and behaviors. Perceptual and motor skills, 82(3), 963-972. https://doi.org/10.2466/pms.1996.82.3.963

Gerdtham, U. G., \& Johannesson, M. (2003). A note on the effect of unemployment on mortality. Journal of health economics, 22(3), 505-518. https://doi.org/10.1016/S0167-6296(03)00004-3

Gorsuch, R. L., \& Key, M. K. (1974). Abnormalities of pregnancy as a function of anxiety and life stress.Psychosomatic Medicine. https://doi.org/10.1097/00006842-197407000-00009

Hieronymus, A. N. (1951). A study of social class motivation: relationships between anxiety for education and certain socio-economic and intellectual variables. Journal of Educational Psychology, 42(4), 193. https://doi.org/10.1037/h0059017

Linn, M. W., Sandifer, R., \& Stein, S. (1985). Effects of unemployment on mental and physical health. American Journal of Public Health, 75(5), 502-506. https://doi.org/10.2105/AJPH.75.5.502

Merriam-Webster. Anxiety. [Online]. Available at https://www.merriam- webster.com/dictionary/anxiety (Accessed on 17th Jan. 2017). 
Montgomery, S. M., Cook, D. G., Bartley, M. J., \& Wadsworth, M. E. (1999). Unemployment pre-dates symptoms of depression and anxiety resulting in medical consultation in young men. International Journal of Epidemiology, 28(1), 95-100. https://doi.org/10.1093/ije/28.1.95

Mykletun, A., Bjerkeset, O., Øverland, S., Prince, M., Dewey, M., \& Stewart, R. (2009). Levels of anxiety and depression as predictors of mortality: the HUNT study. The British Journal of Psychiatry, 195(2), 118-125. https://doi.org/10.1192/bjp.bp.108.054866

National Research Council. (2010). Understanding the changing planet: Strategic directions for the geographical sciences. National Academies Press.

Norberg, M. M., Norton, A. R., Olivier, J., \& Zvolensky, M. J. (2010). Social anxiety, reasons for drinking, and college students. Behavior therapy, 41(4), 555-566. https://doi.org/10.1016/j.beth.2010.03.002

Öner, N., \& Le Compte, A. (1985). Handbook of state-trait anxiety inventory. Bogazici University, Istanbul.

Pharr, J. R., Moonie, S., \& Bungum, T. J. (2011). The impact of unemployment on mental and physical health, access to health care and health risk behaviors. ISRN Public Health, 2012.

Schwarzer, R. (Ed.). (2000). The self in anxiety, stress and depression (Vol. 21). Elsevier.

Scott, K. M., Wells, J. E., Angermeyer, M., Brugha, T. S., Bromet, E., Demyttenaere, K., ... \& Karam, A. N. (2010). Gender and the relationship between marital status and first onset of mood, anxiety and substance use disorders.Psychological medicine, 40(9), 1495-1505. https://doi.org/10.1017/S0033291709991942

Silverman, W. K., Saavedra, L. M., \& Pina, A. A. (2001). Test-retest reliability of anxiety symptoms and diagnoses with the Anxiety Disorders Interview Schedule for DSM-IV: child and parent versions. Journal of the American Academy of Child \& Adolescent Psychiatry, 40(8), 937-944. https://doi.org/10.1097/00004583-200108000-00016

Spence, K. W., Taylor, J., \& Ketchel, R. (1956). Anxiety (drive) level and degree of competition in paired-associates learning. Journal of Experimental Psychology, 52(5), 306. https://doi.org/10.1037/h0043812

Spielberger, C. D. (1983). Manual for the State-Trait Anxiety Inventory STAI (form Y) ("self-evaluation questionnaire").

Spielberger, C. D. (1989). State-trait anxiety inventory: a comprehensive bibliography. Consulting Psychologists Press.

Thoits, P. A. (1987). Gender and marital status differences in control and distress: Common stress versus unique stress explanations. Journal of health and Social Behavior, 7-22. https://doi.org/10.2307/2137137

Williams, CJ. Reassessing the Role of Anxiety in Information Seeking. Master Thesis, University of North Texas. Available at https://digital.library.unt.edu/ark:/67531/metadc9012/m2/1/high_res_d/thesis.pdf (Accessed on 16th Jan. 2017) 2008

Wu, C. C. (2011). High graduate unemployment rate and Taiwanese undergraduate education. International Journal of Educational Development, 31(3), 303-310. https://doi.org/10.1016/j.ijedudev.2010.06.010

Zeidner, M., \& Ben-Zur, H. (1994). Individual differences in anxiety, coping, and post-traumatic stress in the aftermath of the Persian Gulf War. Personality and Individual Differences, 16(3), 459-476. https://doi.org/10.1016/0191-8869(94)90072-8

\section{Copyrights}

Copyright for this article is retained by the author(s), with first publication rights granted to the journal.

This is an open-access article distributed under the terms and conditions of the Creative Commons Attribution license which permits unrestricted use, distribution, and reproduction in any medium, provided the original work is properly cited. 